\title{
Research on Intensive Storage Technology Application Situation and Development Trend
}

\author{
Yinbo $M A^{1, a}$, Hongjian Liu ${ }^{2, b}$ \\ ${ }^{1}$ School of Information, Beijing Wuzi University, Beijing,101149, China \\ ${ }^{2}$ School of Information, Beijing Wuzi University, Beijing,101149, China \\ aemail:yinbo1991@qq.com, bemail:lilylhj@qq.com
}

\begin{abstract}
Keywords: Intensive Storage Technology; Shuttle Plate Shelves; Honeycomb Storage; Modular Dense Storage
\end{abstract}

\begin{abstract}
Intensive storage technology can obtain a higher density of goods store and warehouse space utilization, through the adoption of specific equipment, technologies and solutions. Based on the traditional intensive storage system and the status quo of the application, this article respectively discusses the intensive storage tray gravity type formed in the technology development trend of storage system, the shuttle plate shelves storage system, honeycomb storage system, combined with dense storage system, and respectively analyzed the intensive storage system structure, working principle and applications.
\end{abstract}

\section{Introduction}

In recent years, with the high-speed development of the domestic economy as well as the right to use construction land resources increasingly scarce, how to store the large amount of goods in the limited space and improve the capacity of storage rate is becoming an urgently problem to be solved by the manufacturing enterprise and circulation enterprises in China. intensive storage technology comes into being under the background and requirements. Response to the unit in terms of architectural space, compared with the traditional tunnel type of storage shelves, by reducing the roadway or reduce the channel width, the area of utilization rate reached $50 \%$ or space utilization rate reached more than $40 \%$ of the storage technology, its value lies in the economical use of land, reduce building energy consumption and cost savings.[1]

\section{Intensive storage technology application situation}

Dense storage is within the limited space in order to improve space utilization and a warehouse form dense storage of goods, dense storage technology means for the realization of the dense storage used equipment, technologies and solutions.[2] In today's enterprise applications, dense storage technology is mainly manifested in its devices, or warehouse shelves, more early intensive storage system, mainly used in drive-in rack, movable rack, push back rack and deep place stacker stereoscopic warehouse to achieve intensive storage. Dense storage technology is developing gradually, gradually gained popularity in the enterprise applications. Here on these shelves structural features, working principle, main features and applications.

\section{(a) Drive-in Rack}

Structural features: Bracket type shelf, it is adopted to form between the height and depth of party complete be well versed in the position of channel, generally for three to four layers, channel depth about 10 trays

Working principle: Forklift can be operated access into the channel

Key feature: Through type shelves full fill with relatively high storage density; forklift operation channel and storage space sharing of goods; Simple structure; Cost is low; After the advanced; The low degree of automation

Applications: Suitable for pallet unit and few varieties and large quantities of goods stored 


\section{(b) Movable Rack}

Structural features: Level translation, circulation and vertical circulation is three kinds of structure forms

Working principle: Level translation type or power for human power, realize the operation channel change: horizontal circulation and vertical circulation is dynamic type, realize "goods to people" mode of operation

Key feature: Reduce or cancel the operation channel, improve the storage density: circular movement is only suitable for small goods units: a high degree of automation; Complicated structure and high cost

Applications: Common in small items such as books and materials and components of many varieties, small batch stored

\section{(c) Push Back Rack}

Structural features: A kind of gravity shelves, shelves on the position of each layer with 2 a 3 stacked tray, there is a roller guide rail between each other

Working principle: Thrust by the forklift when loading and unloading, with one end of the warehousing goods will be placed on pallets in turn pressure into the channel, outbound, after the goods taken in front of the back of the goods between the gravity slide outbound side

Key feature: Equivalent to how deep a tray of shelves, storage density is higher, and does not need much advanced goods fork out after, shelf structure is relatively complex

Applications: It is mainly used for forklift access homework, stored on pallet

\section{(d) Deep place stacker Stereoscopic warehouse}

Structural features: Each roadway on both sides of the stacker is arranged above 2 row of shelves, formed on the shelf depth between the multiple position decorate stacker deep stacking machine adopts a pallet fork generally for the double deep place in actual application.[3]

Working principle: By deep a pallet fork on the shelf depth between the parties directly on two or more goods

Key feature: Besides has all the characteristics of a traditional stereoscopic warehouse, reduced the number of stacker roadway, increase the storage density of goods, reduce costs, after advanced within the same column trays

Applications: Application range and the traditional automatic stereoscopic warehouse is the same, but more storage density

\section{Intensive storage technology development trend}

With the development of information technology and computer automatic control technology, there were sprung up a variety of intensive storage, automatic access and intelligent information processing in the integration of new warehouse system, tray gravity storage system, the shuttle plate shelves warehousing system, honeycomb storage system, modular dense storage system etc. The emergence of these new intensive automatic storage technology, has brought the revolutionary change for the development of warehousing, at the same time is also the future development trend of the intensive type storage.

\section{(a) Tray gravity storage system}

Tray gravity storage system by gravity shelves and matching of in-out warehouse stacker and forklift two gravity type is a key part of the shelves with slope slide, slide slope Angle for 23 degrees, commonly installed above have roller, pallet with the aid of gravity can be from the warehouse to slide to the outbound side two roller is without power, in order to ensure the goods can be uniform decline, the distance of every other position on the table set up a set of damping 
roller with guide plates are installed in the entrance end of the passage of goods, goods installed in the outlet channel separation mechanism, the role of the separation mechanism is the outlet of the first separating tray and the back of the tray for the pickup of the forklift and stacker, as shown in figure 1.This kind of gravity type storage system with high intensity, the structure is simple, save energy, use convenient maintenance, and conform to the principle of "first in first out". But there are some disadvantages: the first is the demand is higher, to the environment such as dust, temperature, humidity, tray material will affect the sliding speed of goods; In addition, due to the channel slope leading to the top and bottom shelves on both ends of each part of the waste storage space; And the performance of the damping roller is associated with cargo load, when the weight of the goods storage changes greatly affected use; To make the system safe and reliable running, should not be too much goods quantity, generally not more than 10 second at present, the tray gravity storage system is comparatively mature technology, is widely applied.[4]

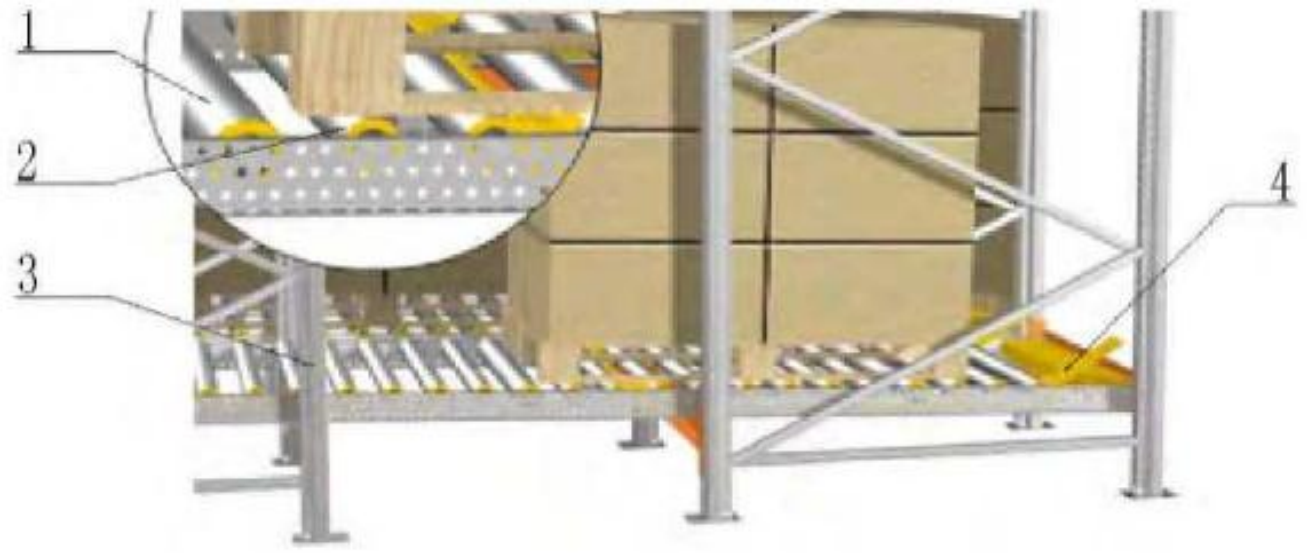

1 The damping roller 2 loose roll 3 storage rack 4 Security separator

Source: INTERROLL company product information.

Figure 1 with damping roller gravity shelves

But the system of the gravity than regular automatic state library shelves requirements higher, because gravity shelves in addition to supporting the weight of the goods will have to support the weight of the many drum and so on the strength and stiffness requirement is generally made library shelves. This system is suitable for large quantities of goods of few varieties by great quantity of storage.

\section{(b) The shuttle plate shelves warehousing system}

The shuttle plate shelves warehousing system is more popular in recent years an intensive storage system. Using battery power, using wireless remote control technology for operation, through the through type goods shelf at the bottom of the track, carrying goods to implement directly.[5] The shuttle plate shelves warehousing system not only has equipment all the advantages of the dynamic type and gravity type shelf, but also avoid the two shelves inevitable drawbacks. Shuttle plate shelf storage system, in the presence of just because the shuttle plate price is quite high, is more difficult to accept, so on the popularization and application. But with the growing popularity of the wireless communication technology and battery technology, the shuttle plate already has a significant cost reduction, especially with the enterprise production cost of land and into the rapidly increase of part cost, taken together the shuttle racking storage system has become a more mainstream intensive storage system, and also is a kind of trend of future dense storage technology. Shuttle plate shelf storage system is shown in figure 2. 


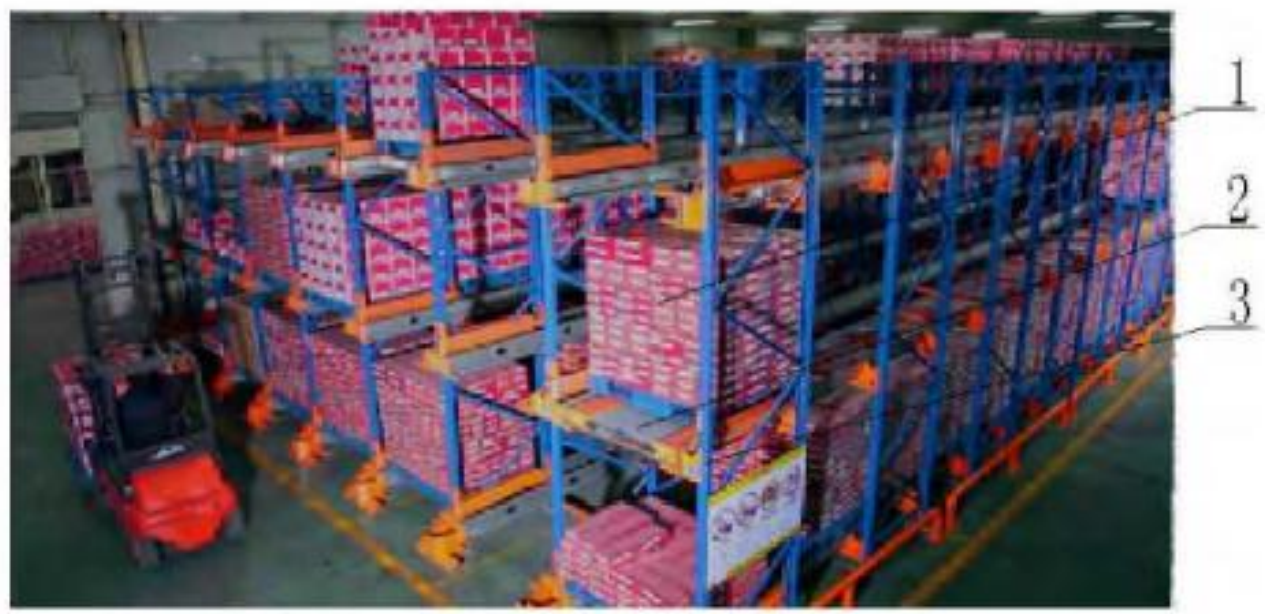

1 Cargo unit 2 Shuttle plate 3 Through type shelf and orbit

Figure 2 shuttle plate shelf storage systems

In traditional shuttle plate shelf storage system, the shuttle plate can only walk along a straight line reciprocating (one-way), therefore needs to be implemented with the aid of in-out warehouse stacker or forklift truck on the transfer between different channel carrying; this will inevitably affect the operational efficiency of the whole storage system. [6] To solve this problem we studied a two-way shuttle plate intensive storage system. The two-way shuttle plate has the function of the vertical cross rail two-way walking along the plane, so that the shuttle plate was able to transfer between different storage channel running, don't have to take up for the stacker or forklift, can improve the efficiency of storage system operation.[7] Two-way shuttle plate and hoist, forklift truck can take the place of stacker and high in-out warehouse operations simplify system structure and reduce the effect of construction cost. Figure 3 is the principle of the bidirectional shuttle plate storage system.

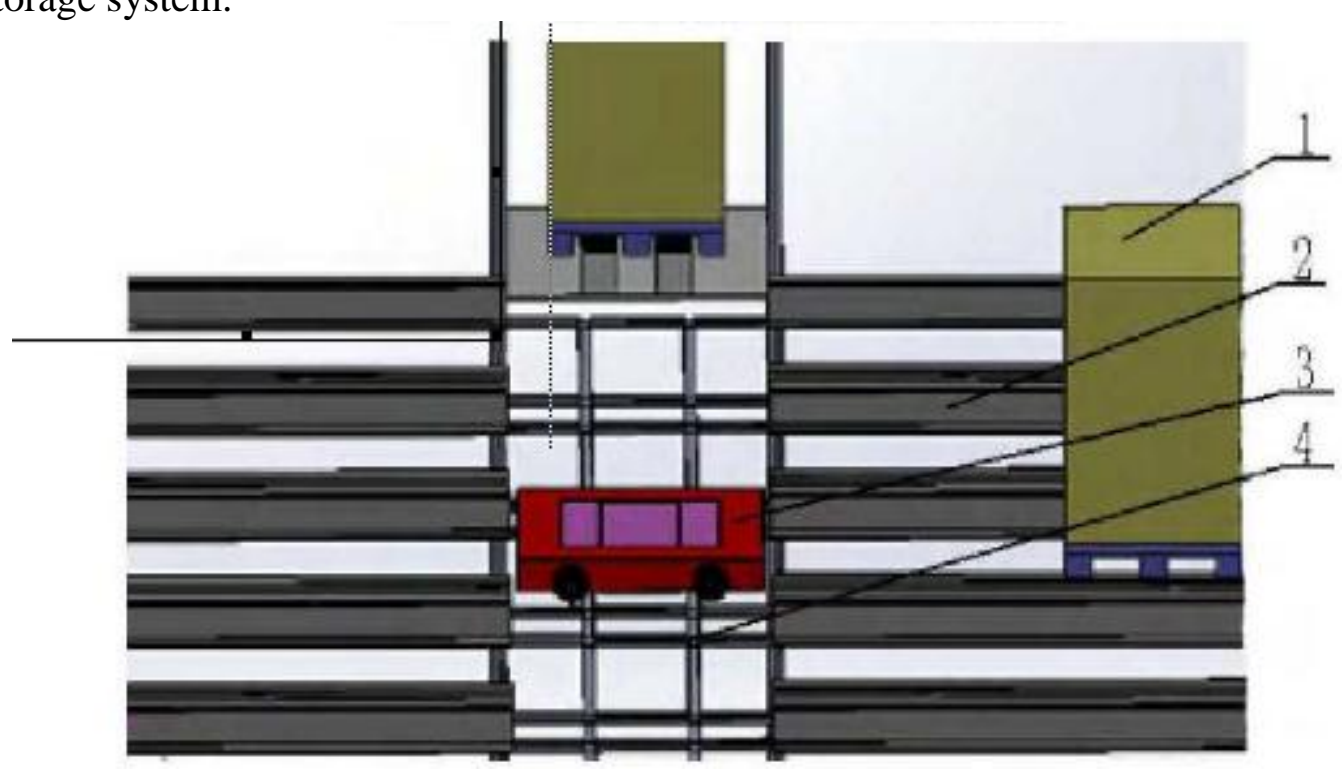

1 Pallet goods 2 Shelves with orbit 3 The bidirectional shuttle car 4 Cross rail

Figure 3 two-way shuttle car storage systems

\section{(c) Honeycomb storage system}

Honeycomb storage technology is a new type of intensive storage technology, storage shelves of grid shaft layout, the orbit of shaft above the cloth has a grid, access to goods can pass in grid orbit double shuttle car to achieve, as shown in figure 4.Due to the storage system is like a beehive, so named honeycomb storage system. This kind of honeycomb storage system high storage density, 
high degree of automation, and can accommodate many car work in parallel at the same time, for the high efficiency, especially suitable for electricity storage points one-piece work environment.

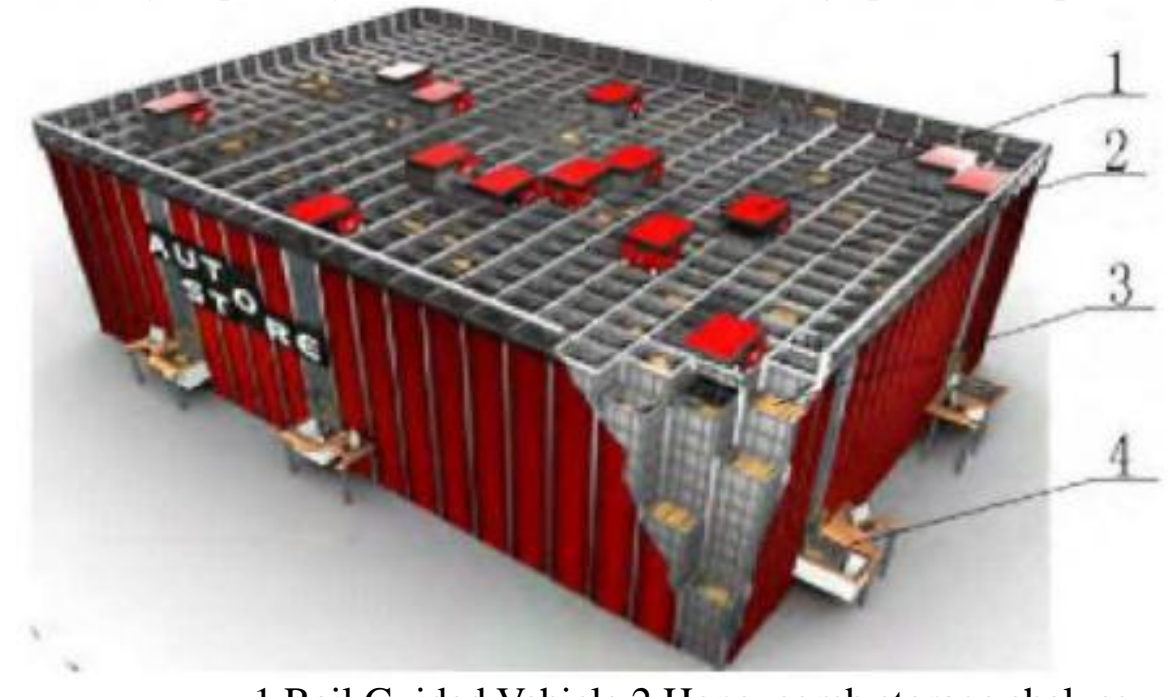

1 Rail Guided Vehicle 2 Honeycomb storage shelves

3 Packing case 4 In and out of the warehouse trestle work

Figure 1 Honeycomb fashion storage systems

The system is mainly composed of grid shelves, two-way shuttle car, stack, crate and control system for the second grid shelf is made of aluminum alloy profiles assembly each shaft closely packed, containers stacked in the shaft and shaft pillar orientation and order, the top of the shaft frame of the trolley track of grid;[8] The car along the top grid can be two-way orbit, the hoisting mechanism on the car from a crate or in a silo, achieve the goods directly 2 cars, power is supplied by batteries is a wireless remote control, flexible operation, can work more than one car at the same time, for the high efficiency. Stack for ins and outs of each stage has a terminal operation, display the information as shown in figure status and provide a simple supply function.

\section{(d) Modular dense storage system}

Modular dense storage system is a variety of forms of intensive integrated storage shelves according to the demand, the complex integration of storage and sorting task, has been applied in some particular industry. Traditional into racking storage system and the gravity type storage system although dense storage level is very high and low cost, but its low degree of automation, access goods efficiency is not high; Although power storage systems and shuttle car storage system of a high degree of automation, but the former need to install a lot of roller and conveyor equipment, which need the shuttle plate, this greatly increased the cost.[9] If the two together effectively, according to the actual needs is resolved into racking storage system and the gravity type storage system is not the problem of high degree of automation, and solves the dynamic storage system and shuttle car storage system to the problem of high cost. 


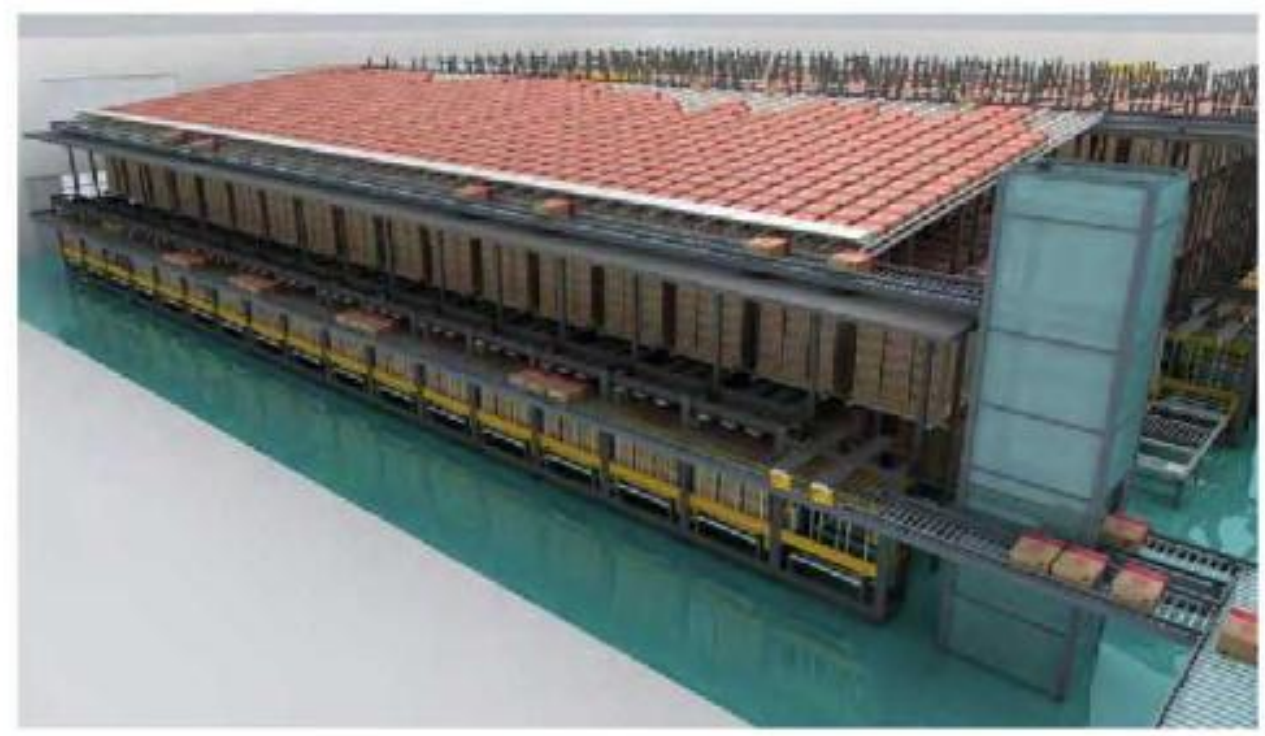

Figure 5 modular dense storage and sorting warehouse

The system consists of warehousing primary storage area and sorting outbound cache area of two parts. Warehousing main storage area by the beam shelves, warehouse stacker, support plates, intensive storage channel, outbound stacker, container stacker crane and empty tray open buttress machine and empty pallet, etc; Sorting outbound buffering by outbound stacker, pillar, intensive storage channel, fluent shelf, small varieties for the hoist, crate crib, empty pallet machine, small brands crate open buttress machine and packing case conveyor, etc. [10]This intensive storage system is not constrained by a simple storage of goods, but joined the sorting outbound buffering, make up for past storage density sorting ability weak and small storage density sorting ability of faults.

\section{Conclusion}

At present, the intensive storage technology is present a high intensity, high efficiency, intelligent, and various forms of combining the development trend. In comparison, the shuttle plate shelf storage system in developing more rapidly in recent years, mainly due to the wireless communication technology and battery technology unceasing development and popularization, which developed on the basis of the bidirectional shuttle plate intensive storage system has more flexible use function, the two-way shuttle plate and hoist cooperatively, it can simplify the effect of the system structure, reduce the construction cost of the system. With the emergence of foreign honeycomb dense storage system, the system has high storage density, at the same time accommodate many car work in parallel, the efficiency is very high, especially suitable for electricity industry storage points one-piece environment operation requirements. In the future as the industry characteristics and the changing of goods form, many proprietary items intensive storage technologies will also be constantly emerging, many intensive storage technology will gradually spread to the enterprise and has been accepted.

\section{Acknowledgements}

The study is supported by Beijing Key Laboratory of Intelligent Logistics System, (BZ0211), and the project of Beijing Wuzi University Yunhe River scholar, high level cultivation project of Beijing Wuzi University (No.0541502703), and Beijing Intelligent Logistics System Collaborative Innovation Center. 


\section{References}

[1] Li Ming. Active innovation application of dense storage technology [J]. Journal of logistics technology and application. 2013(9):116-118

[2] Meng Chunhui. Active intensive automated library goods allocation and task scheduling [D]. Jinan: shandong university, 2014.

[3] Liu Quanwei. Automated multi-layered storehouse goods allocation and task scheduling integrated research [D]. Jinan: Shandong University, 2013.

[4] Cong Lanqiang, Shen Minde, Zhang Yigong. Intensive automatic warehousing technology progress of [J]. Journal of logistics technology, 2014 (10):390-392

[5] Yuan Jianxin, Li Xiaoxia. New shuttle plate dense storage technology application in cigarette finished-parts storage modification design [J] Technology innovation and application, 2015 (4):36-37

[6] Yang Jun. New shuttle plate type full automatic stereoscopic warehouse application research [J]. Journal of logistics technology and applications, 2014 (2):92-95

[7] Xu Jingjing, Liu Xiaojuan. The shuttle racking system and its application [J]. Journal of logistics technology and applications, 2012(2): 69-72.

[8] Song Zhilan. Intensive automatic stereo warehouse system [J]. Journal of logistics technology and application. 2010 (9):90-94

[9] Cui Xiong. Intensive storage shelves application system construction and innovation [J]. Journal of logistics technology and application, 2013 (2):65-69

[10] Xin Yu. Research and application of cigarette logistics center with dense storage system [D]. Beijing: Beijing University of posts and telecommunications, 2013. 